\title{
Enhancing active radial distribution networks by optimal sizing and placement of DGs using modified crow search algorithm
}

\author{
Mohamed Abdelbadea, Tarek A. Boghdady, Doaa Khalil Ibrahim \\ Electrical Power Engineering Dept., Faculty of Engineering, Cairo University, Egypt
}

\begin{tabular}{l} 
Article Info \\
\hline Article history: \\
Received, Apr 132019 \\
Revised Jun 15, 2019 \\
Accepted Jul 2, 2019 \\
\hline
\end{tabular}

\section{Keywords:}

Crow search algorithm

Distributed generation

Multi-objective optimization

Sizing of DGs

Total harmonic distortion

\begin{abstract}
Incorporating many Distributed Generators (DGs) technologies in power system networks has grown rapidly in recent years. Distributed generation (DG) plays a key role in reducing power loss and enhancing the voltage profile in radial distribution networks. However, inappropriate DGs site or size may cut network efficiency; moreover, injecting harmonics is one of the integration concerns of inverter-based DGs. Two-procedure based approach is introduced in this paper. The first procedure solves the DGs siting and sizing problem, as a multi-objective one by improving the voltage profile of the whole distribution network and also reducing its power loss. A weighted sum method is presented to create the Pareto optimal front in this procedure and get the compromised solution by applying a novel metaheuristic optimizer, named Crow Search Algorithm (CSA). A modification on CSA is also proposed and applied to improve its performance. The achieved solution for inverter-based DGs placement and size is checked in the second procedure to make sure the accepted voltage THD at all buses by implementing detailed simulation for the tested system using Matlab/Simulink. The proposed approach has been tested on IEEE 33-bus radial distribution system with photovoltaic DGs. To confirm the superiority of the modified CSA algorithm in terms of quality of solution, its achieved results are compared with the results offered by the original CSA algorithm and published results of some other nature-inspired algorithms.
\end{abstract}

Copyright $@ 2019$ Institute of Advanced Engineering and Science. All rights reserved.

Corresponding Author:

Doaa Khalil Ibrahim,

Department of Electrical Power Engineering,

Faculty of Engineering, Cairo University, Giza, Egypt.

Email: doaakhali173@cu.edu.eg

\section{INTRODUCTION}

Radial distribution systems (RDS) are commonly implemented in rural or suburban areas for their simplest structure and low initial installation cost as they are fed from utility grid at only one end. However, they suffer from several disadvantages. Their main disadvantages are the heavy loaded distributor at its end near to the substation, the customers at the distant end of the distributor face serious voltage fluctuation problem and in addition that distributor faults will cause interruption in supply to large number of consumers connected to that distributor. Actually, the overall power losses within the transmission and distribution systems limit the capability of the radial distribution system. In fact, distribution power loss accounts for the greatest amount of loss as $13 \%$ of the generated energy, which is dissipated as a heat within conducting materials [1]. This non-negligible quantity of losses results in a direct economic impact and also affects the overall capability of RDS.

DGs at the distribution side of the network are projected to play a significant role in satisfying the rapidly increasing world's electricity demand. DGs differ with respect to purpose, voltage level, size, technology and others [2]. In general, DG size ranges from some $\mathrm{kW}$ to hundreds of MW. It can be classified by micro DG for less than $5 \mathrm{~kW}$; small DG from $5 \mathrm{~kW}$ to less than $5 \mathrm{MW}$; medium DG from $5 \mathrm{MW}$ to less 
than $50 \mathrm{MW}$ and finally large distributed generation from $50 \mathrm{MW}$ to less than $300 \mathrm{MW}$ [3]. Based on technology and connection with distribution network, DG can also be classified as reciprocating engines, micro-turbines, combustion gas turbines, fuel cells, photovoltaic systems, small hydro turbines and wind turbines [4]. The main advantageous applications of DG can be summarized as less expensive standby generation instead of grid extension and improving system performance. Besides, DG units using renewable energy resources offer environmentally friendly solutions than the traditional generation by avoiding the large measure of $\mathrm{CO} 2$ emissions. On the other hand, most DG technologies use power electronic converters to manage the ability of these generators. Such converters negatively affect the grid harmonics level that need to be carefully monitored to guarantee the allowable limits and ensure satisfactory operation of the system [5].

Determining the suitable place and size of DG is vital to get greatest benefits from integrating DG with distribution systems. Inappropriate sitting may scale back the advantages and drive to overall poor system performance [6]. Several approaches are proposed and developed in literature to decide the right site and size of DG units achieving one or several goals with or without network reconfiguration. The analytical and improved analytical methodologies for minimizing power loss have been introduced in [6-7]. A power stability index is employed in [8] to decide the more sensitive bus for DG unit placement, and an exploration rule was introduced for getting the optimum size to reduce power loss. Several researchers have also applied different metaheuristic techniques for getting the optimum location and size of DG units. In [9], the genetic algorithm (GA) is primarily used for solving multi-objective optimization for the most effective size and allocation of DG units with multi-system constraints whereas in [10-11], the particle swarm optimization (PSO) has been implemented to select the optimum size and placement of one DG unit. Both GA and PSO are joined in [12] to improve their performance for determining the DG optimum size and placement.

In recent years, there has been an increasing amount of literature on applying very recent developed optimization tools for optimally DG allocation such as cuckoo search, bacterial foraging optimization algorithm, flower pollination algorithm, backtracking search optimization, ant colony optimization and teaching learning-based optimization [13-18]. During most of these optimization approaches, the generation, constraints of bus voltage and branch loading are incorporated in the fitness function as penalty factors to meet a valid solution such that all optimal power flow variables stay within their permissible limits.

In the recent decade, the new Crow Search Algorithm (CSA) is applied in several research studies to get the optimal size and site of DGs [19-23]. The simultaneous optimal placement of DGs and capacitor units in RDS is studied in [20]. Reducing the power loss and improving the voltage profile of the RDS using multiple DGs were the goals of $[21,23]$, while maximizing the overall saving and reducing the network losses were the main objectives of [22]. Obtaining the optimal size and site of DG and DSTATCOM in practical distribution system, to reduce the distribution system loss, is fully introduced in [19].

In present work; modified CSA is implemented to formulate multi-objective function for getting optimal DG size and allocation. It is applied for single DG or multiple DGs units to reduce the active power losses and improve the voltage profile in RDS. The proposed technique will be tested on IEEE 33-bus test radial system. This paper will be organized as follows: problem formulation is presented in Section 2, while in Section 3 the metaheuristic CSA is introduced with the proposed changes. In Section 4, detailed simulation results are discussed. CSA algorithm and the modified one are compared against some other nature inspired algorithms in Section 5; and finally the conclusions are drawn in Section 6.

\section{OPTIMAL PLACEMENT AND SIZING PROBLEM FORMULATION}

This section will discuss briefly the applied method for load flow analysis while the mathematical formulation of the objective function for optimum DGs placement and sizing will be introduced in details.

\subsection{Load Flow Analysis}

The simple forward-backward sweep method introduced in [24] is applied here to solve the RDS load flow analysis and calculate the overall power loss and bus voltages at all buses. It begins at the end bus and precedes backwards the source node. The convergence is checked using the node voltage calculated in backward sweep. If the obtained voltage has less difference than the convergence criterion, the process will end, but if the voltage does not meet convergence limit, forward sweep begins to compute the voltages at each bus starting from the feeder source bus.

According to the small sample network shown in Figure 1, the current in the branch section line $\mathrm{I}_{\mathrm{x}}$ and the voltage $V_{y}$ at node ' $y$ ' are computed according to (1), known the load active and reactive powers $\left(P_{1 x} \cdot Q_{1 x}\right)$ at node ' $x$ ' \& the branch resistance and reactance $\left(R_{x} \cdot X_{x}\right)$ respectively and the voltage $V_{x}$ at node ' $\mathrm{X}$ '. Real power loss in the branch section connecting nodes $\mathrm{x}$ and $\mathrm{y}$ is expressed in (2): 


$$
\begin{aligned}
& I_{x}=\left(\frac{P_{1 x}+j Q_{1 x}}{V_{x}}\right) V_{y}=V_{x}-I_{x}\left(R_{x}+j X_{x}\right) \\
& P_{\operatorname{loss}(x . y)}=\left(\frac{P_{x}{ }^{2}+Q_{x}{ }^{2}}{\left|V_{x}\right|^{2}}\right) \times R_{x}
\end{aligned}
$$

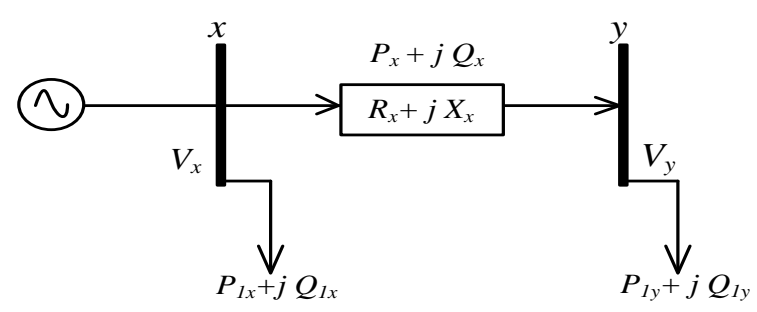

Figure 1. Sampled distribution system for load flow analysis

\subsection{Mathematical Problem Formulation}

\subsubsection{Multi-Objective Approach for Optimal DG Sizing and Placement}

As a matter of fact, the bus voltage of a typical RDS often experiences fluctuations and may collapse under some critical loading conditions with increased load demand. Therefore, the main purpose of the present work is to get the optimal location and size of multiple added DGs in RDS while achieving minimum real network loss and improved voltage profile. Accordingly, the objective function can be divided into two parts: power loss minimization and voltage deviation minimization. These two single objective functions are merged to form a multi-objective optimization problem, whose (OF) is the cost function. As given in (3), the overall multi-objective function is expressed using a linear combination of the two objectives $\mathrm{OF}_{1}$ and $\mathrm{OF}_{2}$ via the weighted sum method, where $\mathrm{w}_{1}, \mathrm{w}_{2}$ are the weighting factors for $\mathrm{OF}_{1}$ and $\mathrm{OF}_{2}$ respectively.

$$
\mathrm{OF}=\mathrm{w}_{1} \times \mathrm{OF}_{1}+\mathrm{w}_{2} \times \mathrm{OF}_{2}
$$

Assuming that the studied RDS that has a rated network voltage $\mathrm{V}_{\text {rated }}$ (equals $1.0 \mathrm{pu}$ ), consists of number of buses equals No_b and number of branch lines is No_lines. Each branch $\mathrm{j}$ connecting two buses has a branch resistance $R_{j}$, carries a current with the value $I_{j}$ and the voltage at the $i_{\text {th }}$ bus is denoted by $V_{i}$. Therefore the two objectives $\mathrm{OF}_{1}$ and $\mathrm{OF}_{2}$ are expressed by (4) and (5). As clearly shown, the total active power loss of the system $\left(\mathrm{P}_{\mathrm{T}_{-} \text {loss }}\right)$ can be calculated based on the summation of the power loss in all RDS branches, while the overall voltage deviation $\left(\mathrm{VD}_{\mathrm{T}}\right)$ is calculated based on the summation of the square value of bus voltage deviation $\left(\mathrm{VD}_{\mathrm{i}}\right)$ at all buses.

$$
\begin{aligned}
& \mathrm{OF}_{1}=\operatorname{minimizing} \text { total active power loss }\left(\mathrm{P}_{\mathrm{T}_{-} \text {loss }}\right)=\min \sum_{\mathrm{j}=1}^{\mathrm{No} l i n e s} \mathrm{I}_{\mathrm{j}}^{2} \mathrm{R}_{\mathrm{j}} \\
& \mathrm{OF}_{2}=\text { minimizing overall voltage deviation }\left(\mathrm{VD}_{\mathrm{T}}\right)=\min \sum_{\mathrm{i}=1}^{\mathrm{No} \_\mathrm{b}} \mathrm{VD}_{\mathrm{i}}=\min \sum_{\mathrm{i}=1}^{\mathrm{No} b}\left(\mathrm{~V}_{\mathrm{i}}-\mathrm{V}_{\text {rated }}\right)^{2}
\end{aligned}
$$

In fact, the weighted sum method is applied here to create the Pareto optimal front. This might be noted that each objective functions in (3) is normalized via dividing it by its base value which makes the objective function dimensionless and normalized and that prevents any scaling problem as discussed in [25].

\subsubsection{Constraints}

The applied formulation as a multi-objective function is subjected several constraints: network operating constraints and DG constraints. The operating constraints define the voltage limits at all network buses, line capacity limits of different lines and the active power balance equations as follows:

$$
\begin{aligned}
& V_{\text {min }} \leq V_{i} \leq V_{\text {max }} \text { for } \mathrm{i}=1 \text { to No_b } \\
& I_{j} \leq I_{\max }(j) \text { for } \mathrm{j}=1 \text { to No_lines }
\end{aligned}
$$


$\mathrm{P}_{\text {supply }}+\sum_{\mathrm{k}=1}^{\mathrm{N}} \mathrm{P}_{\mathrm{DG}_{-} \mathrm{k}}=\mathrm{P}_{\text {load }}+\mathrm{P}_{\mathrm{T}_{-} \text {loss }}$

Where:

$V_{\text {min }}$ and $V_{\max }$ are the smallest and the greatest allowable voltage $V_{i}$ at each bus i. Such limits are expressed according to [26] by $\pm 5 \%$ of the rated network voltage $V_{\text {rated }}$ for all network buses.

$I_{\max }(j)$ is the maximum current carrying capacity [26-27], the current $I_{j}$ flowing in the line $j$ should be less than $I_{\max }(j)$.

$\mathrm{P}_{\text {supply }}$ is the active power supplied by the grid as the original primary source, while $\mathrm{P}_{\text {load }}$ is the total active load of the system. $P_{D G_{-}}$is the active power penetrated by $k_{t h}$ DG unit for N no. of DG units.

On the other hand, some constraints about the size of each added $D G$ at $k_{t h}$ bus $\left(P_{D_{-} k}\right)$ and the overall DG penetration should also be considered as follows:

$$
\begin{aligned}
& \mathrm{P}_{\mathrm{DG} \_ \text {min }} \leq \mathrm{P}_{\mathrm{DG} \_\mathrm{k}} \leq \mathrm{P}_{\mathrm{DG} \_ \text {max }} \\
& \mathrm{P}_{\mathrm{T}_{-} \mathrm{DG} \_ \text {min }} \leq \sum_{\mathrm{k}=1}^{\mathrm{N}} \mathrm{P}_{\mathrm{DG} \_\mathrm{k}} \leq \mathrm{P}_{\mathrm{T}_{-} \text {DG_max }}
\end{aligned}
$$

Where:

$\mathrm{P}_{\mathrm{DG} \_ \text {min }}$ and $\mathrm{P}_{\mathrm{DG} \_ \text {max }}$ denote the minimum and maximum allowed output active power of $\mathrm{k}_{\mathrm{th}} \mathrm{DG}$ unit respectively,

$\mathrm{P}_{\mathrm{T}_{\text {_DG_min }}}$ and $\mathrm{P}_{\mathrm{T}_{-} \text {DG_max }}$ are the total minimum and maximum allowed output of all added DG units (N units), assuming that all DG units generate active power only.

\subsubsection{Ensuring the voltage $T H D v$ at All Buses}

Distorted currents absorbed by harmonic-producing loads also distort the supply voltage as they pass through system impedance. Therefore, a distorted voltage can be presented to other end users. The power quality industry has developed certain indices to assess service quality related to distortions caused by harmonics. The total harmonic distortion is one of the most commonly used indices for measuring the overall waveform harmonic content taken into account the contribution of all harmonics components [28]. IEEE Std. $519^{\text {TM }}$ - 2014 is developed for utilities and customers to limit the harmonic content, the boundaries on the total harmonic distortion on the output voltage $\left(\mathrm{THD}_{\mathrm{v}}=\frac{\sqrt{\sum_{\mathrm{h}=2}^{\infty} \mathrm{v}_{\mathrm{h}}^{2}}}{\text { Fundamental voltage }}\right)$ are listed in Table 1 for distribution networks levels.

In the second procedure of the proposed approach, the impact of DGs on harmonics is investigated. The achieved former solution for DGs placement and size is tested to check $\mathrm{THD}_{\mathrm{V}}$ at all buses by simulating the RDS using Matlab/Simulink where the installed DGs type is assumed inverter-based. When the limits are still confirmed, the achieved solution is accepted. However, if the limits are violated, another solution is selected or inserting a mitigation filter is suggested.

Table 1. Voltage Distortion Limits in Distribution Networks According to IEEE Std. 519TM_2014

\begin{tabular}{ccc}
\hline Bus voltage $\mathrm{V}$ at point of common coupling & Individual Harmonic (\%) & Total Harmonic Distortion (\%) \\
\hline $\mathrm{V} \leq 1.0 \mathrm{kV}$ & 5.0 & 8.0 \\
$1 \mathrm{kV}<\mathrm{V} \leq 69 \mathrm{kV}$ & 3.0 & 5.0 \\
\hline
\end{tabular}

\section{MODIFIED CROW SEARCH ALGORITHM (CSA) OPTIMIZER}

Crow search algorithm is a recent metaheuristic algorithm developed by Askarzadeh [29], inspired on the intelligence behavior conducted by crows of hiding their excess food in a place and get it back when needed. CSA has been applied for different problems with different constraints. As an algorithm based on population, the size of the flock is confirmed by $\mathrm{N}_{\mathrm{C}}$ individuals (crows) which are of $\mathrm{n}$ - dimensional where $\mathrm{n}$ denotes the problem dimensions. Each crow (individual) is assumed to have the capability of remember the best visited location to hide food. The position is then modified according to Pursuit \& Evasion behaviors. Pursuit: a crow $\mathrm{j}$ follows crow $\mathrm{i}$ with the purpose to discover its hidden place. The crow i does not notice the presence of the other crow, as consequence the purpose of crow $\mathrm{j}$ is achieved. Evasion: the crow i knows about the presence of crow $\mathrm{j}$ and in order to protect its food, crow i intentionally takes a random trajectory. This behavior is simulated in CSA through the implementation of a random movement. The type of behavior considered by each crow $\mathrm{i}$ is determined by an awareness probability (AP). The flight length (FL) parameter 
indicates the magnitude of movement from crow position towards the best position of crow $\mathrm{j}$ [30-31]. In fact, CSA consumes less time than other metaheuristic methods as it has fewer parameters to adjust: AP and FL, so it is easy to be implemented. To offer a good balance between diversification and intensification in CSA, the AP can control both factors. When AP decreases, the algorithm tends to search in local optima therefore, the intensification increases. When AP increases, the algorithm tends to search in global optima therefore, the diversification increases.

In [19-23], the original CSA is applied to get the optimal size and site of DGs where the variable represents the position of the crows in the space is assumed randomly based on lower $\left(L_{B}\right)$ and upper $\left(U_{B}\right)$ bounds of the variable. A modified CSA is proposed in this article, where the CSA variable is calculated depending on Gaussian and Cauchy density functions [32], which are shown in Figure 2.

a) The Gaussian function or the normal distribution is defined as a continuous function that approximates exact binomial distribution for the events. It provides probability for some real observations to fall between any two predefined real numbers or limits as the function tends to zero on either side. Its curve resembles the shape of a bell, thus it is informally known as the bell curve. For the mean or expectation of the distribution $(\mu)$ and the variance $\left(\sigma^{2}\right)$, the probability density of the normal distribution is expressed by $F(x)=\frac{1}{\sqrt{2 \pi \sigma^{2}}} e^{\frac{(x-\mu)^{2}}{2 \sigma^{2}}}$. In paper work, the variance is assumed to be unity (i.e. $\sigma^{2}=1$ ).

b) The Cauchy distribution is a continuous probability distribution known as Cauchy-Lorentz distribution or Breit-Wigner distribution. It is expressed by: $F(x)=\frac{1}{\pi} \frac{t}{t^{2}+x^{2}}$ for $t>0$ as a scale parameter.

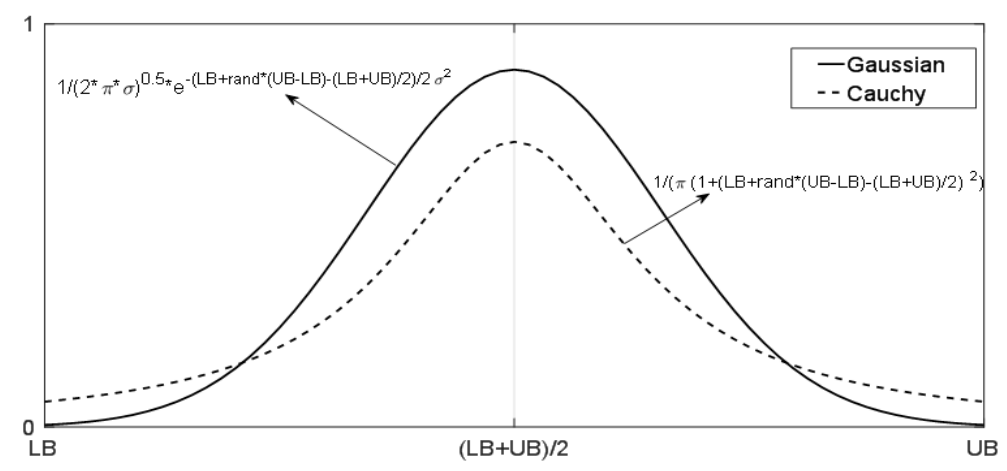

Figure 2. Gaussian and Cauchy distribution functions

In order to check the performance of the modified CSA on larger-scale optimization problems, four well-known benchmark functions, discussed in [33], are solved in 10 dimensions using CSA (original algorithm), CSA-G (based on Gaussian distribution), and CSA-C (based on Cauchy distribution). The obtained results are summarized in Table 2. As shown, CSA-G outperforms the other methods.

Table 2. Performance of Modified CSA for Benchmark Test Functions

\begin{tabular}{llccccc}
\hline Function Name & \multicolumn{1}{c}{ Function Formulation } & Search Space & Optimal Value & CSA & CSA-G & CSA-C \\
\hline Sphere Function & $\sum_{i=1}^{n} X_{i}^{2}$ & {$[-100,100]$} & 0 & $9.54 \mathrm{e}-13$ & $1.39 \mathrm{e}-36$ & $2.69 \mathrm{e}-35$ \\
Rosenbrock Function & $\sum_{i=1}^{n}\left(100\left(x_{i+1}-X_{i}^{2}\right)^{2}+\left(x_{i}-1\right)^{2}\right)$ & {$[-30,30]$} & 0 & 1.52 & 0.75 & 0.77 \\
Griewank function & $\frac{1}{4000} \sum_{i=1}^{n}\left(X_{i}\right)^{2}-\prod_{i=1}^{n} \cos \left(\frac{x_{i}}{\sqrt{i}}\right)+1$ & {$[-600,600]$} & 0 & 0.0099 & 0.0059 & 0.229 \\
Schwefel function & $\sum_{i=1}^{n}\left|x_{i}\right|-\prod_{i=1}^{n}\left|x_{i}\right|$ & {$[-10,10]$} & 0 & $9.37 \mathrm{e}-6$ & $3.29 \mathrm{e}-18$ & $1.13 \mathrm{e}-17$ \\
\hline
\end{tabular}

\section{TEST SYSTEM AND SIMULATION RESULTS}

The system under study is IEEE 33-bus radial distribution network shown in Figure 3. Without DG installation, it has a total load of $3.72 \mathrm{MW}, 2.3 \mathrm{MVAR}$ and real power loss of $211 \mathrm{~kW}$. All system buses are not within the limits $\pm 5 \%$ of the rated network voltage and the least voltage is 0.9037 pu at bus 18 [34].

In this paper, two-procedure based approach is introduced. The first one solves the DG siting and sizing problem as a multi-objective one by improving the voltage profile of RDS and reducing its power loss 
as two conflicting functions using a modified CSA-G. Then the solution is checked in the second procedure to ensure accepted $\mathrm{THD}_{\mathrm{v}}$ at all buses. In the following sections, achieved results are introduced. The results for solving optimal DG placement and sizing problem using multi-objective optimization approach are introduced in first part. The impact of $\mathrm{DG}$ on $\mathrm{THD}_{\mathrm{V}}$ is investigated in the second one.

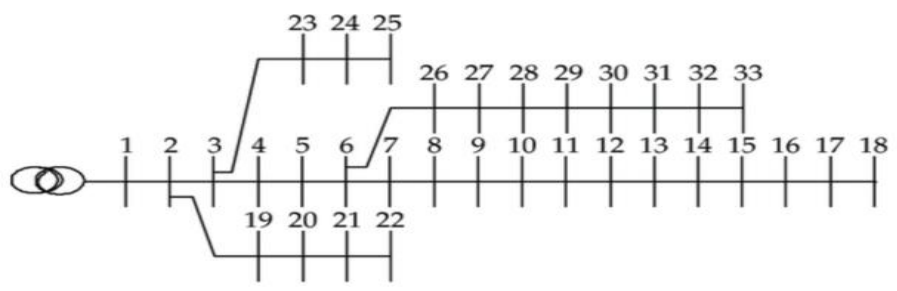

Figure 3. IEEE 33-bus radial distribution network

\subsection{Results of Optimal DG Sizing and Placement}

Installation of single and multiple DGs are considered in the tests, which ended with a comparative study of all cases.

\subsubsection{Case 1: Installing Single DG}

In this case, a single DG unit is assumed to be integrated to the 33-bus RDS. By applying different values for weighting factors $\mathrm{w}_{1}, \mathrm{w}_{2}$, sets of solutions are achieved using CSA-G. Figure 4-a) shows the solutions set or the Pareto front which consists of 10 trade-off solutions (values of $\mathrm{w}_{1}, \mathrm{w}_{2}$, change from 0.1 to 0.9 with a step of 0.1 ). The point of intersection of the two curves denotes the compromised solution. The Pareto front for such optimal solution ensures that a DG size of $3114.5 \mathrm{~kW}$ can be installed at bus 7 to give the least voltage deviation of $0.02342 \mathrm{pu}$, and lowest reduction in real power loss from $211 \mathrm{~kW}$ without DG installation to $118.5 \mathrm{~kW}$ with a reduction of about $43.83 \%$ at weighting factors of $0.47 \& 0.53$.

\subsubsection{Case 2: Installing Multiple DG units}

In this case, the multi-objective optimization problem is resolved by installing two DG units simultaneously to the tested RDS and three simultaneous DG units. The Pareto front curves using the modified CSA-G are shown in Figure 4-b) and Figure 4-c).

a. Point B represents the compromised solution for adding two DG units of size 1344.7 and $1161.3 \mathrm{~kW}$ at bus 12 and 30 respectively to provide the minimum voltage deviation at $0.007107 \mathrm{pu}$, and real power has reduced to $94.18 \mathrm{~kW}(55.36 \%$ reduction without DG installation) at weighting factors $0.52 \& 0.48$.

b. Point $\mathrm{C}$ characterizes the compromised solution for adding three DG units of 846.2, 931.6 and 1296.2 $\mathrm{kW}$ to be installed at buses 13, 24 and 31. Such sizes ensure the minimum voltage deviation at 0.0066 $\mathrm{pu}$, and reduction of about $62.5 \%$ in real power loss $(79 \mathrm{~kW})$. The weighting factors $w_{1}, w_{2}$ are $0.58 \&$ 0.42 respectively in this case.

From the quick comparison of the Figure 4 graphs, it can be concluded that multiple DG installations will reduce the real power losses more than using a single DG unit and also the voltage deviation is decreased significantly. Actually, the size of the added DGs regarding the reduced loss reduction can be economically evaluated by a simple economical index. Besides, the effect of adding DGs on the voltage of all buses can be assessed using the index of the average voltage deviation.

For further evaluate the proposed changes on CSA, the three compromised solutions A, B and C, are fully summarized for all applied methods of CSA (original CSA, CSA-G, and CSA-C) in Table 3 according to such proposed indices:

$$
\begin{aligned}
& \text { Economical Index }=\frac{\sum_{\mathrm{k}=1}^{\mathrm{N}} \mathrm{P}_{\mathrm{DG}_{\_} \mathrm{k}}}{\mathrm{P}_{\mathrm{T}_{\perp} \text { loss }} \text { without } \mathrm{DG}^{-\mathrm{P}_{\mathrm{T}_{-} \text {loss }} \text { with DG }}} \\
& \text { Voltage Index (p. u) }=\text { Average deviation per bus }=\sqrt{\frac{\sum_{i=1}^{\mathrm{No}_{\mathrm{b}}}\left(\mathrm{V}_{\text {rated }}-\mathrm{V}_{\mathrm{i} \text { with DG}}\right)^{2}}{\mathrm{No}_{\mathrm{b}}}}
\end{aligned}
$$




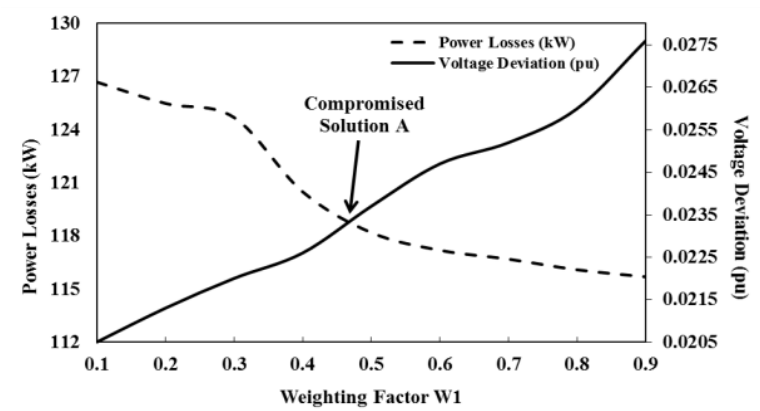

(a). One DG unit

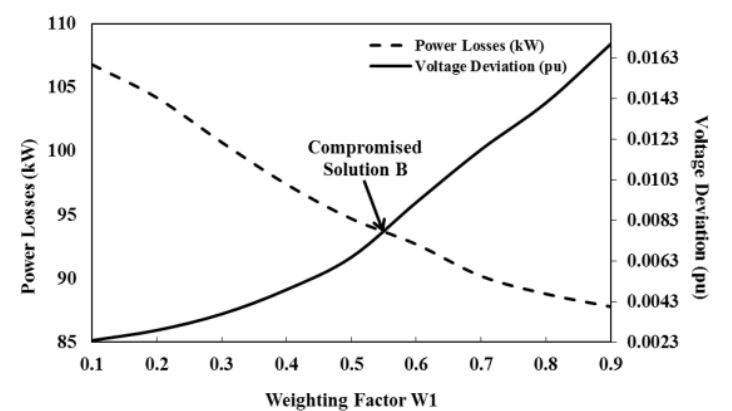

(b). Two DG units

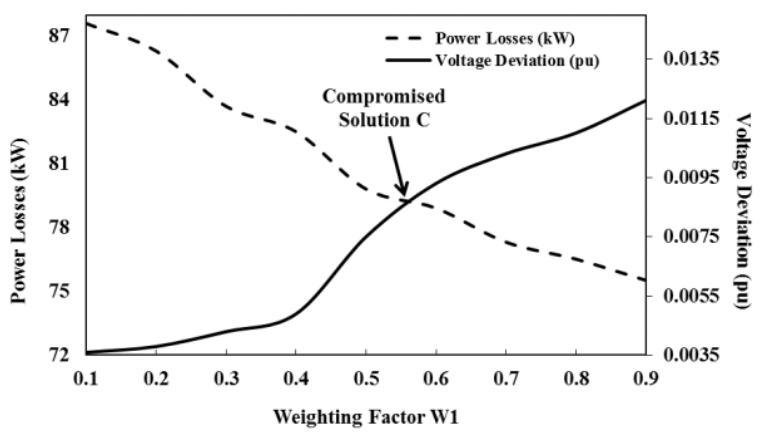

(c). Three DG units

Figure 4. Compromised solutions using modified CSA-G

Table 3. Comparison of the Three Compromised Solutions (A, B And C) for Single and Multiple DG Units

\begin{tabular}{|c|c|c|c|c|c|c|c|c|}
\hline $\begin{array}{l}\text { No. of } \\
\text { DG units }\end{array}$ & $\begin{array}{l}\text { Applied } \\
\text { Algorithm }\end{array}$ & $\begin{array}{l}\text { DG Size } \\
(\mathrm{kW})\end{array}$ & @ Bus & $w_{1}, w_{2}$ & $\begin{array}{c}P_{T \_l o s s} \\
(\mathrm{~kW})\end{array}$ & $\begin{array}{c}\text { Ec. } \\
\text { Index }\end{array}$ & $\begin{array}{c}\text { Voltage } \\
\text { Index (pu) }\end{array}$ & $\begin{array}{c}\text { Lowest bus voltage } \\
\text { (pu @ bus) }\end{array}$ \\
\hline \multirow{3}{*}{ One } & CSA & 2534.7 & 8 & $0.42,0.58$ & 132.1 & 32.3 & 0.022804 & $0.9532 @$ bus 18 \\
\hline & CSA-G & 3114.5 & 7 & $0.47,0.53$ & 118.5 & 33.6 & 0.02664 & $0.9534 @$ bus 18 \\
\hline & CSA-C & 2579.3 & 6 & $0.61,0.39$ & 153.3 & 44.7 & 0.02009 & 0.9534@bus 33 \\
\hline \multirow{3}{*}{ Two } & CSA & $1073.5,1326.2$ & 16,26 & $0.48,0.52$ & 103.9 & 22.4 & 0.021105 & $0.9537 @$ bus 33 \\
\hline & CSA-G & $1344.7,1161.3$ & 12,30 & $0.52,0.48$ & 94.18 & 21.45 & 0.01468 & 0.9752@bus 33 \\
\hline & CSA-C & $2494.3,811.7$ & 28,16 & $0.35,0.65$ & 121 & 36.73 & 0.00798 & 0.982@bus 25 \\
\hline \multirow{3}{*}{ Three } & CSA & $1251.3,1271.9,611.6$ & $14,24,30$ & $0.38,0.62$ & 87 & 25.28 & 0.01834 & $0.9601 @$ bus 33 \\
\hline & CSA-G & $1296.2,931.6,846.2$ & $31,24,13$ & $0.58,0.42$ & 79 & 23.29 & 0.01655 & $0.9736 @$ bus 18 \\
\hline & CSA-C & $1061.3,1215.1,1047.2$ & $14,26,31$ & $0.47,0.53$ & 99.6 & 29.83 & 0.00644 & $0.9823 @$ bus 25 \\
\hline
\end{tabular}

\subsection{Results Of Investigating $T H D v$}

The aim of this section is to investigate the impact of adding the previous optimal calculated DG units to the RDS with the assumption that all added units are inverter-based PV units to get the worst condition of $\mathrm{THD}_{\mathrm{V}}$. Detailed Simulink model of the studied RDS (IEEE-33 bus) is developed in phasor mode as it calculates the node and the branch voltage representing sinusoidal voltages and currents at a particular frequency. Firstly, the system is simulated without connecting any DG units, and without the presence of any harmonic-producing loads which ensures $0 \%$ for $\mathrm{THD}_{\mathrm{V}}$ as expected at all buses. Then three other scenarios are investigated as illustrated in Figure 5. Such cases represent the three compromised solutions A, B and C using the modified CSA-G:

a) $1^{\text {st }}$ scenario: $3114.5 \mathrm{~kW}$ PV unit is connected at bus 7. As shown the voltage at all buses is distorted within the permissible limit.

b) $\quad 2^{\text {nd }}$ scenario: $1344.7 \mathrm{~kW}$ PV unit is connected at bus 12 and $1164.25 \mathrm{~kW} \mathrm{PV}$ unit is installed at bus 30 ; the results ensure that all buses are contaminated with harmonics within the permissible boundaries.

c) $\quad 3^{\text {rd }}$ scenario: $1296.2 \mathrm{~kW}$ PV unit is added at bus $31,931.6 \mathrm{~kW}$ PV unit is added at bus 24 while 846.2 $\mathrm{kW}$ PV unit is connected to bus 13. As illustrated all buses voltage are distorted within accepted limit.

As clearly shown, that the bus where an inverter-based PV system as a DG unit is installed has almost the highest $\mathrm{THD}_{\mathrm{V}}$ in most of the simulated cases. Besides, the distortion on other neighboring buses also increases, which means that neighboring buses are significantly affected; however the actual number of affected buses depends on the location of DG within the RDS. The $\mathrm{THD}_{\mathrm{V}}$ of the worst bus condition in all

Enhancing active radial distribution networks by optimal sizing and placement of ... (Mohamed Abdelbadea) 
studied scenarios results has increased to almost $1.97 \%$ compared with the original case before DG addition, however it is still satisfying the limits of 3\% according to the IEEE Std. 519TM - 2014. Therefore, the achieved size and place of added DG units for the sake of improving the voltage profile and reducing the overall power system loss are accepted on the power quality issue of injected harmonics.

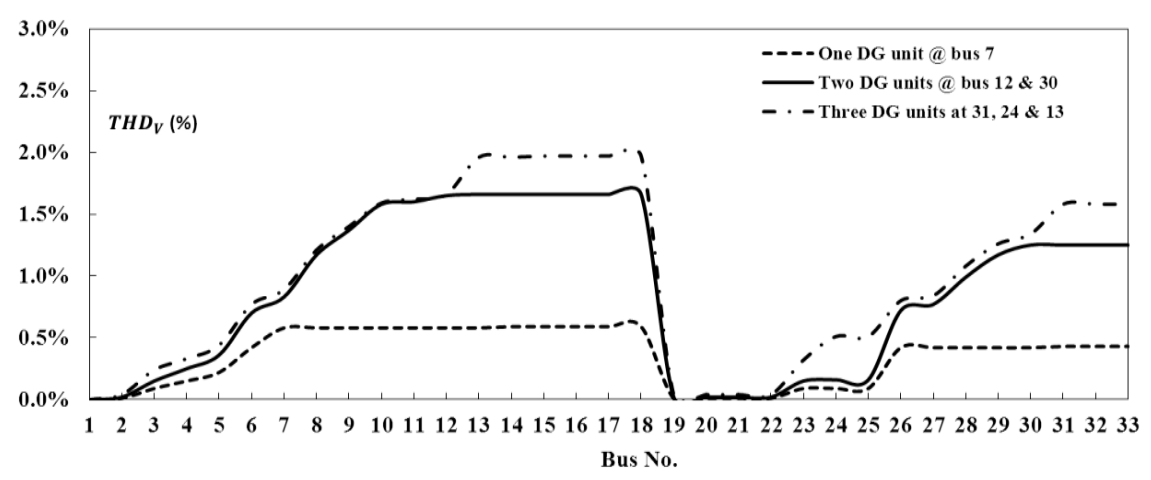

Figure 5. Impact of installing PV-based DGs (based on CSA-G) on $\mathrm{THD}_{\mathrm{V}}$

\section{EXAMINING PROPOSED MODIFICATION FOR CSA}

To confirm the superiority of the proposed CSA-G and CSA-C algorithms over other algorithms in terms of quality of solution, the results of the original CSA algorithm and the modified one are compared against the results offered by other nature-inspired algorithms [35-36]. Such comparison is carried out to meet the goal of simultaneously minimize real power loss and improve voltage profile over IEEE 33 bus system using three DG units. The results are tabulated in Table 4, in which the performance of CSA, CSA-G and CSA-C and are compared with the documented results of PSO in [36], GA in [36], GA-PSO in [36] and TLBO in [35]. From Table 4, it may be noted that the proposed CSA-G offers a minimum value of power loss among all the algorithms referred there in. The voltage deviation obtained by the proposed CSA-G is not better than the original CSA but is better than the GA and PSO variants and the overall voltage profile of the system also gets improved, also CSA-G has the best economical index among all other algorithms.

Table 4. Investigating Modified CSA Performance Over Other Methods

\begin{tabular}{|c|c|c|c|c|c|c|c|}
\hline \multirow[b]{2}{*}{$\begin{array}{l}\text { Algorithm } \\
\text { Ref. }\end{array}$} & \multicolumn{2}{|l|}{ Optimal DG } & \multicolumn{3}{|c|}{ Loss reduction evaluation } & \multicolumn{2}{|c|}{ Voltage improvement } \\
\hline & Size (MW) & @ Bus & $\begin{array}{l}\text { Loss } \\
(\mathrm{pu})\end{array}$ & $\begin{array}{l}\text { Reduction } \\
(\%)\end{array}$ & $\begin{array}{c}\text { Ec. } \\
\text { Index }\end{array}$ & $\begin{array}{c}\text { Voltage } \\
\text { Index (pu) }\end{array}$ & $\begin{array}{c}\text { Lowest bus voltage } \\
\text { (pu @ bus) }\end{array}$ \\
\hline TLBO in [35] & $1.1826,1.1913,1.1863$ & $12,28,30$ & 0.1246 & $40.90 \%$ & 41.20 & 0.005773 & $0.9829 @$ bus 25 \\
\hline PSO in [36] & $1.1768,0.9816,0.8297$ & $8,13,32$ & 0.1053 & $50.09 \%$ & 28.26 & 0.03186 & $0.9806 @$ bus 30 \\
\hline GA-PSO in [36] & $0.925,0.863,1.2$ & $11,16,32$ & 0.1034 & $50.99 \%$ & 27.66 & 0.01938 & $0.9808 @$ bus 25 \\
\hline CSA & $1.251,1.271,0.611$ & $14,24,30$ & 0.087 & $58.76 \%$ & 25.28 & 0.01834 & $0.961 @$ bus 33 \\
\hline
\end{tabular}

\section{CONCLUSION}

In this paper, a multi-objective optimization was applied to search for the optimal DG sizing and placing. DG is added in distribution networks for improving the voltage profile and reducing system loss keeping the injected harmonics values within accepted limits as a main power quality issue. The optimization problem is formulated from two conflicted goals, the total real power loss and the overall voltage deviation. A weighted sum method is presented to create the Pareto front and get the best compromised solution. The considered optimization problem is solved using modified CSA algorithm based on Gaussian distribution (CSA-G) for IEEE 33-bus radial distribution network in case of adding one or multiple DG units. Proposed economical and voltage indices are applied to check the achieved solutions of single, two or three DG units. A comparative study for CSA and the modified CSA-G and CSA-C for mathematical benchmark test functions depicts the better performance of the proposed CSA-G in terms of accuracy. It ensures that CSA-G is capable of enhancing the original CSA performance. Regarding the optimal DG sizing and location, it can be observed that the proposed method is able to find out the optimal location and size of DG, while, at the 
same time, it reduces the real power loss and improves the voltage profile of the system. Upon achieving the compromised solution, the tested system is investigated for satisfying the voltage total harmonic distortion limits when incorporating PV based DG units according to the IEEE Std. 519TM - 2014. Besides, the superiority of CSA-G performance is confirmed when compared against some other algorithms, hence, it can be deduced that the proposed CSA-G algorithm is a good choice over the original CSA and other reported algorithms for solving optimization problems.

\section{REFERENCES}

[1] Khodr HM, Olsina FG, Jesus PMDO-D, Yusta JM, "Maximum savings approach for location and sizing of capacitors in distribution systems", Electric Power Systems Research, Vol. 78, pp. 1192-203, 2008.

[2] Ackermann T, Andersson G, Söder L., "Distributed generation: A Definition", Electric Power Systems Research, Vol. 57, pp. 195-204, 2001.

[3] Acharya N, Mahat P, Mithulananthan N, "An analytical approach for DG allocation in primary distribution network", International Journal of Electrical Power and Energy Systems, Vol. 28, pp. 669-78, 2006.

[4] W El-Khattam, M.M.A Salama, "Distributed generation technologies, definitions and benefits", Electric Power Systems Research, Vol. 71, pp. 119-128, October 2004.

[5] IEEE Std 519тM-2014 (Revision of IEEE Std 519-1992) "IEEE Recommended Practice and Requirements for Harmonic Control in Electric Power Systems".

[6] Duong Quoc Hung, Mithulananthan Nadarajah, R. Bansal, "Analytical Expressions for DG Allocation in Primary Distribution Networks", IEEE Transactions on Energy Conversion, Vol. 25, No. 3, pp. 814-820, October 2010.

[7] Duong Quoc Hung, Nadarajah Mithulananthan, "Multiple Distributed Generator Placement in Primary Distribution Networks for Loss Reduction", IEEE Transactions on Industrial Electronics, Vol. 60, pp. 1700-1708, April 2013.

[8] M.M. Amana, G.B. Jasmona , H. Mokhlisa , A.H.A. Bakara, "Optimal placement and sizing of a DG based on a new power stability index and line losses", International Journal of Electrical Power \& Energy Systems, Vol. 43, pp. 1296-1304, December 2012.

[9] A.A. Abou El-Elaa, S.M. Allama, M.M. Shatlab, "Maximal optimal benefits of distributed generation using genetic algorithms", Electric Power Systems Research, Vol. 80, pp. 869-877, July 2010.

[10] W. El-Khattam, Y. Hegazy, M. Salama, "An integrated distributed generation optimization model for distribution system planning", IEEE Transactions on Power Systems, Vol. 20, No. 2, pp. 1158- 1165, May 2005.

[11] W. Prommee, W. Ongsakul, "Optimal multi-distributed generation placement by adaptive weight particle swarm optimization", International Conference on Control, Automation and Systems, Oct. 2008, pp. 1663-1668, Korea.

[12] M.H. Moradi, M. Abedini, "A combination of genetic algorithm and particle swarm optimization for optimal DG location and sizing in distribution systems", International Journal of Electrical Power \& Energy Systems, Vol. 34, pp. 66-74, January 2012.

[13] Zahra Moravej, Amir Akhlaghi "A novel approach based on cuckoo search for DG allocation in distribution network", International Journal of Electrical Power \& Energy Systems, Vol. 44, pp. 672-679, January 2013.

[14] Mohamed Imran A, Kowsalya M, "Optimal size and siting of multiple distributed generators in distribution system using bacterial foraging optimization", Swarm and Evolutionary Computation, Vol. 15, pp. 58-65, April 2014.

[15] Eyad S. Odaa, Abdelazeem A. Abdelsalama, Mohamed N. Abdel-Wahaba,, Magdi M. El-Saadawib, "Distributed generations planning using flower pollination algorithm for enhancing distribution system voltage stability", Ain Shams Engineering Journal, Vol. 8, pp. 593-603, 2017.

[16] A. El-Fergany, "Optimal allocation of multi-type distributed generators using backtracking search optimization algorithm", International Journal of Electrical Power \& Energy Systems, Vol. 64, pp. 1197-1205, January 2015.

[17] A. El-Fergany, "Study impact of various load models on DG placement and sizing using backtracking search algorithm", Applied Soft Computing, Vol. 30, pp. 803-811, May 2015.

[18] Hamid Falaghi, Mahmood-Reza Haghifam, "ACO Based Algorithm for Distributed Generation Sources Allocation and Sizing in Distribution Systems", Power Tech, 2007 IEEE Lausanne, pp.555-560, July 2007.

[19] Surajit Sannigrahi and Parimal Acharjee, "Implementation of crow search algorithm for optimal allocation of DG and DSTATCOM in practical distribution system", 2018 International Conference on Power, Instrumentation, Control and Computing (PICC), January 2018.

[20] Hassan Barati and Mohsen Shahsavari, "Simultaneous Optimal Placement and Sizing of Distributed Generation Resources and Shunt Capacitors in Radial Distribution Systems using Crow Search Algorithm", in International Journal of Industrial Electronics, Control and Optimization, Vol. 1, No. 1, pp. 27-40, June 2018.

[21] M. Nageswara Rao, N. Sumathi, V.S.N.K. Chaitanya and K.Amarendranath, "Multiple DG allocation by crow search algorithm for power loss reduction", 2017 IEEE International Conference on Power, Control, Signals and Instrumentation Engineering (ICPCSI), pp.790-795, 2017.

[22] Sherif M. Ismael,Shady H. E. Abdel Aleem and Almoataz Y. Abdelaziz, "Optimal sizing and placement of distributed generation in Egyptian radial distribution systems using crow search algorithm", 2018 International Conference on Innovative Trends in Computer Engineering (ITCE), Aswan, Egypt, pp. 332-337, 2018.

[23] Menna S. El-Saeed, Mohamed A. El-Hameed, Amal F. Abd El Gwaad, "Crow Search Algorithm for Allocation of Multi-Type Distributed Generation in Unbalanced Radial Distribution System", The Egyptian International Journal of Engineering Sciences and Technology, Vol. 25, pp. 7-23, 2018. 
[24] J. A. Michline Rupa, S. Ganesh, "Power Flow Analysis for Radial Distribution System Using Backward/Forward Sweep Method," Engineering and Technology International Journal of Electrical and Computer Engineering, Vol. 8, No.10, pp.1628-1632, 2014.

[25] Wilfried Jakob, Christian Blume, "Pareto optimization or cascaded weighted sum: a comparison of concepts", Algorithms, Vol. 1, No. 7, pp. 166-185, 2014.

[26] Arif Wazir, and Naeem Arbab, "Analysis and Optimization of IEEE 33 Bus Radial Distributed System Using Optimization Algorithm", Journal of Emerging Trends in Applied Engineering, Vol. 1, No. 2, pp.17-21, 2016.

[27] Cruz, M. R. M., Fitiwi, D. Z., Santos, S. F., Catalão, J. P. S., "Influence of distributed storage systems and network switching/reinforcement on RES-based DG integration level", 13th International Conference on European Energy Market (EEM), pp. 1-5, 2016.

[28] Saša Vlahinic, Dalibor Brnobic, and Nino Stojkovic, "Indices for Harmonic Distortion Monitoring of Power Distribution Systems", IEEE Transactions on Instrumentation and Measurement, Vol. 58, No. 5, pp. 1771-1777, May 2009.

[29] Askarzadeh, A., "A novel metaheuristic method for solving constrained engineering optimization problems: Crow search algorithm", Computers and Structures, Vol. 169, pp. 1-12, 2016.

[30] Emery, N.J.; Clayton, N.S. The Mentality of Crows: Convergent Evolution of Intelligence in Corvids and Apes", Science, Vol. 306, pp. 1903-1907, December 2004.

[31] Holzhaider, J.C.; Hunt, G.R.; Gray, R.D. Social learning in New Caledonian crows", Learning \& Behavior, Vol. 38, No. 3, pp. 206-219, 2010.

[32] Na Luo and Feng Qian, "Estimation of Distribution Algorithm Sampling under Gaussian and Cauchy Distribution in Continuous Domain", 2010 8th IEEE International Conference on Control and Automation, Xiamen, China, June 9-11, pp. 1716- 1720, 2010.

[33] Mirjalili, S., "The Ant Lion Optimizer', Advances in Engineering Software", Vol. 83, pp. 80-98, May 2015.

[34] S.A. ChithraDevi, L. Lakshminarasimman, R. Balamurugan, "Stud Krill herd Algorithm for multiple DG placement and sizing in a radial distribution system," International Journal of Engineering Science and Technology, Vol. 20, No. 2, pp. 748-759, April 2017.

[35] Sultana, S., Roy, P.K.,"Multi-objective quasi-oppositional teaching learning based optimization for optimal location of distributed generator in radial distribution systems", International Journal of Electrical Power and Energy Systems, Vol. 63, pp. 534-545, 2014.

[36] Moradi, M.H., Abedini, M.: 'A combination of genetic algorithm and particle swarm optimization for optimal DG location and sizing in distribution systems', International Journal of Electrical Power and Energy Systems, Vol. 34, pp. 66-74, 2012.

\section{BIOGRAPHIES OF AUTHORS}
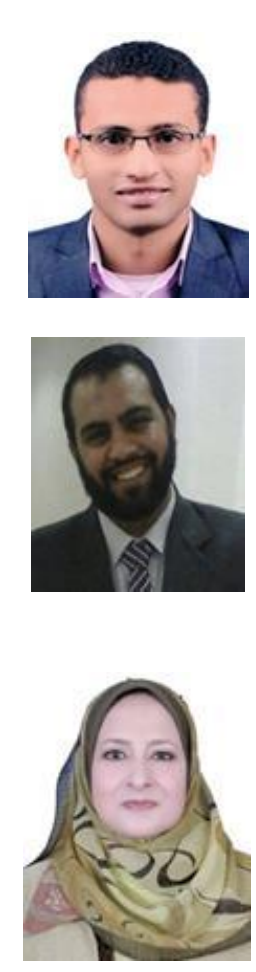

Mohamed Abdelbadea Abdelghany. He was born in Egypt in 1986. He received the B.Sc. from Shoubra Faculty of Engineering, Benha University in 2008 with a grade V.good with Owner degree. Currently, he is pursuing the M.Sc. degree in Electrical Power Engineering Dept., Cairo University, Egypt. From 2008 to 2010 he worked as an Electrical design engineer. From 2010 till now, he is an Electrical engineer in Arab Contractor Company, Cairo, Egypt. $\mathrm{He}$ is a Trainer in the field of Electrical Engineering since September 2017. His research interests include power system, utilization and generation of electric power and renewable energy sources. His email address is: mabdelbadea24@gmail.com.

Tarek A. Boghdady. He was born in Egypt in March 1982. He received the M.Sc. and Ph.D. degrees in electrical power and machines engineering from Cairo University, Egypt, in 2011 and 2016, respectively. From 2005 to 2016, he was a Teaching Assistant with Cairo University. In 2016, he became an Assistant Professor with Cairo University. His research interests include optimization, neural networks, FACTS, HVDC as well as utilization and generation of electric power, distributed generation and renewable energy sources.

Doaa Khalil Ibrahim. She was born in Egypt in Dec. 1973. She received the M.Sc. and Ph.D. degrees in digital protection from Cairo University, Egypt, in 2001 and 2005, respectively. In 2005, she became an Assistant Professor with Cairo University. In 2011, she became an Associate Professor. From Dec. 2016, she became a Professor with Cairo University. She is IEEE Senior Member since 2013. From 2005 to 2008, she contributed to a World Bank Project in Higher Education Development in Egypt. From January 2009 till Nov. 2014, she has contributed to the Program of Continuous Improvement and Qualifying for Accreditation in Higher Education in Egypt. Her research interests include digital protection of power systems as well as utilization and generation of electric power, distributed generation and renewable energy sources. 